\title{
"A REDE NOSSA DE CADA DIA": UM ESTUDO DE CASO SOBRE A REDE DE DORMIR ARTESANAL NA ASSOCIAÇÃO XIQUE-XIQUE EM PEDRO II- PIAUÍ
}

Clarissa Borges Nonato

Universidade Federal de Pernambuco

clarissapi@ig.com.br

Virgínia Pereira Cavalcanti

Universidade Federal de Pernambuco

Cavalcanti.virginia@gmail.com

Resumo: Este artigo trata da relação entre design, artesanato e desenvolvimento sustentável local, tendo como propósito analisar as ações do design como instrumento a serviço do desenvolvimento sustentável local. Para tanto, desenvolveu-se um estudo de caso com uma observação direta e cuidadosa sob a rede de dormir artesanal da Associação XiqueXique, objeto de estudo desta pesquisa, nos seguintes aspectos: dimensão sociocultural e econômica, identificação da técnica de produção, tipos de redes e elementos figurativos e, ainda, as inserções de design a serviço do desenvolvimento sustentável local. Os resultados sinalizaram que o artefato possui um elevado valor sociocultural e importância econômica para as tecelãs e que o design pode ser um meio para melhorar a competitividade das redes de dormir artesanais. Mas para que essas inserções de design se revertam em desenvolvimento sustentável local na Associação Xique-Xique é necessário uma ação conjunta e eficaz em toda a cadeia produtiva. É importante levar em consideração não somente o produto, mas aspectos relacionados, por exemplo, à comunicação e mercado.

Palavras-chave: Cultura material, Design, Artesanato, Rede de dormir, Desenvolvimento sustentável local.

\begin{abstract}
This article is about the connection between design, crafts and local sustainable development, analyzing the actions of design as a tool in the service of local sustainable development. The research was developed as of a direct and careful observation in the hammock craft of Xique-Xique Association. The case study approached the socio-cultural and economic dimension, the production of technical identification, types of networks and figurative elements and the influence design. The results signaled that the artifact has a high socio-cultural value and economic importance to the weavers and that design can be a means to improve the competitiveness of handmade hammocks. But for reverse the inserts design in local sustainable development in the Xique-Xique Association is necessary effective joint action across the all production chain. It is important to take into
\end{abstract}


consideration not only the product but related aspects, for example, management, communication and market.

Key words: Material culture, Design, Crafts, Hammock, Local Sustainable Development.

\section{INTRODUÇÃO}

No município de Pedro II, Piauí, encontra-se uma tradicional produção de redes de dormir artesanais. De acordo com Carvalho (2009), a atividade começou no final do século XIX. A igreja católica implantou e, posteriormente, organizou o setor através da criação dos grupos comunitários de produção e da fundação da primeira cooperativa de tecelagem na localidade. Quanto à qualidade dessa produção, Cascudo (2003) revela, conforme censo de 1956, que as redes de dormir de Pedro II eram as melhores para dormir que se fabricavam no Piauí. Redes feitas à mão, de luxo, para presente e de perfeito acabamento adquiridas, também, por pessoas residentes em outros Estados.

Ao longo dos anos, transmitido entre gerações de tecelões, o ofício ganhou força e passou a ser um forte traço da identidade cultural local, uma vez que revela aspectos relacionados aos hábitos e costumes representativos da região e que dão sentido de pertencimento a essa população. Como pontua Castells $(1999$, p. 22) que "a identidade é uma fonte de significados e experiências de um povo, construída com base em atributos culturais, e que se constituem como referencial para os próprios indivíduos de uma comunidade".

Desse modo, o artesanato das redes de dormir, sua técnica de produção, experiências e conhecimentos que foram compartilhados no decorrer do tempo, ganha sentido em virtude das referências simbólicas, crenças, códigos e normas praticadas em coletividade e que representam a identidade dos grupos sociais que 0 produzem. Nesse sentido, Borges (2011, p. 217) explica que "o artesanato é um dos meios mais importantes de representação da identidade de um povo. Através dele, não só os materiais e as técnicas, mas também os valores coletivos são fortemente representados."

Somado a essa dimensão sociocultural, surge o aspecto econômico, a atividade é um importante meio de geração de renda e movimenta, na região, uma cadeia produtiva que envolve o artesão, associações e cooperativas de artesanato, os fornecedores de matéria-prima, vendedores do produto acabado e o consumidor. Assim, pode ser considerada uma atividade com potencial para promoção do desenvolvimento sustentável local que "[...] deve mobilizar e explorar as potencialidades locais e contribuir para elevar as oportunidades sociais e a viabilidade e competitividade da economia local; ao mesmo tempo, deve assegurar a conservação dos recursos naturais locais [...]" (BUARQUE, 2008, p. 25).

Nesse processo, o design pode colaborar com o desenvolvimento de ações em harmonia com os recursos locais e os modos de vida das pessoas. Em sua ação sistêmica, pode melhorar a competitividade ${ }^{1}$ da produção artesanal, interpretando e valorizando o amplo contexto em que a atividade acontece. Manzini (2008, p.32)

\footnotetext{
1 "Capacidade das empresas ou organizações de formular e implementar estratégias concorrenciais, que Ihe permitam conservar, de forma duradoura, uma posição sustentável no mercado." (ECIB, 1993, p.4).
} 
pontua que o design "sob uma perspectiva sustentável, deve proteger e desenvolver a diversidade biológica, sociocultural e tecnológica, dando, entre outras coisas, uma maior importância aos produtos artesanais locais."

Diante desse contexto, a presente pesquisa desenvolvida através dos métodos de abordagem dialética e de procedimento do estudo de caso, tem como objetivo geral: analisar as ações do design como instrumento a serviço do desenvolvimento sustentável local na rede de dormir artesanal na Associação Xique-Xique, em Pedro IIPiauí, em sua dimensão sociocultural e econômica. E como objetivos específicos: caracterizar a dimensão sociocultural e econômica em que se desenvolve a produção da rede de dormir artesanal; identificar as técnicas de tecer, os tipos de redes de dormir e os elementos figurativos tecidos e, por fim, mapear as ações de design, aplicadas à rede de dormir artesanal da Associação Xique-Xique, a serviço do desenvolvimento sustentável local.

Nessa perspectiva, o design pode ser uma ferramenta estratégica capaz de agregar valor e gerar competitividade às redes de dormir artesanais da Associação Xique-Xique e, desse modo, colaborar para promoção do desenvolvimento sustentável local. Assim, segue a pergunta que norteou a pesquisa: Como o design, aplicado às redes de dormir artesanais, tem promovido o desenvolvimento sustentável local na Associação Xique-Xique em Pedro II-Piauí?

\section{DESENVOLVIMENTO}

\subsection{Problema de estudo}

Atualmente, a rede de dormir artesanal de Pedro II passa por um processo de desvalorização no mercado local. Não consegue concorrer, no preço, com a rede sol a $\mathrm{sol}^{2}$, produzidas na localidade, e, numa menor proporção, com a rede industrializada vinda de outros Estados. A competição pelo preço entre os vendedores de redes locais é outro agravante, uma vez que para garantir a venda, precisam diminuir, ainda mais, o valor do produto. Como pontua a vendedora ${ }^{3}$ de redes: "Fica difícil com esse pessoal vendendo a preço muito baixo [...] Se ela vende uma Três panos a $\mathrm{R} \$ 48,00$ e chega um e bota $R \$ 47,00$, ela diminui e vende a $R \$ 46,00 . "$

Mudanças culturais relacionadas ao uso do artefato também são determinantes para essa desvalorização. O hábito de dormir em redes deixou de ser comum. Hoje, o artefato é mais utilizado para os momentos de breve descanso. Desse modo, o consumidor adquire a rede de dormir em menor quantidade e a utiliza com menos frequência, o que compromete o seu volume de venda. Segundo Cardoso (2012, p.38), "[...] os tempos mudam e mudam com ele o significado das coisas que parecem fixas." Assim, as mudanças no contexto cultural determinaram novos usos e sentidos para as redes de dormir artesanais, comprometendo o seu alcance comercial.

Resistindo a essas transformações econômicas e socioculturais, encontra-se a rede de dormir artesanal da Associação Xique-Xique. No propósito de revitalizar e dar

\footnotetext{
${ }^{2}$ Rede de dormir com pano em tecido de algodão industrializado. São associados a sua feitura etapas manuais, como a colocação dos punhos e aplicação de varandas.

${ }^{3}$ Os nomes dos participantes da pesquisa (tecelãs, designers, gestores e comerciantes locais) foram omitidos do texto, pois não houve autorização para divulgá-los. As tecelãs, maior amostra, foram identificadas por meio de uma sequência numérica.
} 
sustentabilidade a sua tradicional produção, programas como o Artesanato Solidário ${ }^{4} \mathrm{e}$ instituições de fomento como o $\operatorname{SEBRAE}^{5}$ vem promovendo a inserção do design, trabalhando desde a organização social, melhoria da qualidade dos processos produtivos, como também, o desenvolvimento de novos produtos, no propósito de contribuir para geração de renda na Associação Xique-Xique. Assim, coube à pesquisa analisar, através dos dados coletados, se essas ações de design na rede de dormir artesanal colaboraram para a promoção do desenvolvimento sustentável local na Associação Xique-Xique.

\subsection{Metodologia da pesquisa}

O estudo foi desenvolvido em duas etapas. A primeira referente à pesquisa bibliográfica em que foram delimitadas as dimensões teóricas. A segunda, caracterizada, de acordo com Yin (2010), como um estudo de caso único e holístico, pois utiliza uma unidade de análise, a Associação Xique-Xique, em Pedro II-Piauí.

Nesse universo, foi realizada uma observação direta sob a rede de dormir artesanal da Associação Xique-Xique nos seguintes aspectos: dimensão sociocultural e econômica; identificação da técnica de produção, tipos de redes e elementos figurativos e, ainda, as inserções de design a serviço do desenvolvimento sustentável local.

O desenvolvimento prático desse estudo de caso aconteceu em três fases:

a) Aplicação do piloto de pesquisa para definição da amostra a ser investigada;

b) Pesquisa de campo na Associação Xique-Xique;

c) Análise e cruzamento dos dados adquiridos.

Foram desenvolvidos dois protocolos de pesquisa: um para o piloto de pesquisa e outro para o estudo de caso, propriamente dito.

\subsubsection{Protocolos de pesquisa}

Segundo Yin (2010, p.106), "O protocolo é uma maneira importante para aumentar a confiabilidade da pesquisa do estudo de caso e se destina a orientar o investigador na realização da coleta de dados de um caso único".

\footnotetext{
${ }^{4}$ O Programa Artesanato Solidário, criado em 1998, tornou-se a OSCIP Artesol no ano de 2002. Atuou na Associação Xique-Xique no período de 2000 a 2002. As suas ações estão voltadas para apoiar e salvaguardar o fazer artesanal de tradição cultural, promovendo a autonomia dos artesãos e o desenvolvimento cultural, social e econômico de suas comunidades. Trabalha com uma tecnologia de caráter social, atuando em três eixos: formação, capacitando os artesãos para valorização cultural e no domínio de estratégias para o mercado; articulação, promovendo o trabalho em rede dos agentes da cadeia produtiva do artesanato de tradição cultural; geração de renda, apoiando a comercialização do artesanato de tradição cultural e estimulando a sustentabilidade econômica dos grupos. (fonte: www.artesol.org.br, acesso em 13 de maio de 2015)

5 “A missão do SEBRAE é promover a competitividade e o desenvolvimento sustentável das micro e pequenas empresas. As atribuições do SEBRAE nacional em relação ao Artesanato são: Executar as ações nacionais, promover projetos inovadores, desenvolver e testar metodologias para atendimento das necessidades do setor, coletar e disseminar as informações para os SEBRAE|UF (representações locais) coordená-los e apoiá-los, e ainda articular e apoiar ações junto às ações da Gestão Pública. Cada SEBRAE |UF tem a finalidade de formular estratégias de execuções locais, articular parcerias no âmbito estadual e municipal e executar as ações de atendimento do setor em consonância com as diretrizes do SEBRAE nacional." (AZEVEDO; CAVALCANTI, 2013). (Fonte: www.acasa.org.br , acesso em 26/03/2015)
} 
As dimensões abordadas, para o estudo de caso, foram construídas considerando as seguintes variáveis do desenvolvimento sustentável local: exploração das potencialidades socioculturais e econômicas locais; envolvimento dos agentes locais e competitividade da economia local.

Já o protocolo da pesquisa piloto considerou quatro variáveis para análise: variável organizacional para verificação das associações, enquanto agentes para o desenvolvimento sustentável local; variável do processo de produção para identificação da capacidade produtiva, processos de produção, tipos de redes de dormir e elementos figurativos, existência de espaço de produção e convívio social; variável socioeconômica para verificação da viabilidade da produção através dos preços praticados, custos relacionados à matéria-prima, renda das tecelãs e formas de comercialização; variável de design para identificação da ocorrência de inserções de design nas redes de dormir artesanais.

\subsubsection{Resultados da pesquisa piloto}

A pesquisa piloto foi realizada com as presidentes das duas associações de tecelagem locais, AAPII ${ }^{6}$ e Xique-Xique. Os dados foram coletados por meio de entrevista semiestruturada. As questões investigadas foram divididas em três categorias: comercialização, produção e capacitação da produção.

Sobre as tecelãs, os dados coletados apontaram um equilíbrio no número de mulheres cadastradas nas duas associações. No entanto, a Xique-Xique apresenta um maior número de tecelãs produtoras de redes. São quinze tecelãs em comparação as três que produzem na AAPII.

Com relação à produção, a Xique-Xique apresentou uma maior capacidade de produção. Os tipos ${ }^{7}$ de redes produzidas nas duas associações são praticamente os mesmos: Tapuerãna, Três panos, Seis panos, Batida ou Caruá, Olho de Pombo, Duas Capas e Quadro virado. Há um equilíbrio, também, nas tramas desenvolvidas: Olho de pombo, Catada, Tapuerãna e Caruá ou Batida. Os elementos figurativos são mais variados nas redes da Associação Xique-Xique. As etapas de produção, as matériasprimas utilizadas e os equipamentos rústicos são comuns às duas associações. A XiqueXique mantém um espaço de produção comum, enquanto, a AAPII desativou a oficina de produção, o que contribuiu para a desmobilização das tecelãs.

Quanto à comercialização, revela que os preços das redes dependem do modelo e do tipo de matéria-prima utilizada. A Xique-Xique trabalha com preço um pouco inferior ao da AAPII. Com relação à renda obtida, na Xique-Xique é entre $\mathrm{R} \$$ 50,00 a $\mathrm{R} \$ 100,00$ e na AAPII é entre $\mathrm{R} \$ 80,00$ e $\mathrm{R} \$ 100,00$ por rede produzida. Uma rede completa leva de 15 a 20 dias para ser confeccionada. E quanto à capacitação, passaram por inserções de design e nas áreas de comercialização e gestão.

A análise desses dados determinou a escolha da Associação Xique-Xique como amostra mais coerente para o desenvolvimento da pesquisa. Dado a maior capacidade de produção e organização social mais coesa.

\footnotetext{
${ }^{6}$ Associação dos Artesãos de Pedro II

${ }^{7}$ Os nomes dos tipos de redes de dormir é uma referência às tramas em que são produzidas. Daí os tipos de redes e as tramas possuírem a mesma denominação.
} 


\subsection{Pesquisa de campo}

Nessa fase, com auxílio do protocolo do estudo de caso, foram aplicadas entrevistas estruturadas e semiestruturadas e as técnicas de observação direta e artefatos físicos, com registros fotográficos e filmagens do processo de produção das redes de dormir artesanais. As amostras selecionadas para pesquisa foram caracterizadas da seguinte forma: dez tecelãs da Xique-Xique entre 40 e 70 anos; os dois designers que trabalharam na associação; os gestores do Programa SEBRAE de Artesanato, Programa Artesanato Solidário e a secretária de turismo do município de Pedro II, representando o poder público, e os comerciantes locais dos insumos e da comercialização direta do produto acabado.

\section{4- Análise e cruzamento de dados}

Segundo Lakatos e Marcone (2003), análise e cruzamento dos dados constituem-se no núcleo central da pesquisa. A primeira evidencia as relações entre o fenômeno estudado e o seu contexto; a segunda procura dar um significado mais amplo às respostas, vinculando-as a outros conhecimentos. Nesse sentido, as informações coletadas foram analisadas e interpretadas através do cruzamento dos dados adquiridos por meio do referencial teórico e do que foi colhido no contexto real. Todos esses procedimentos produziram subsídios para se analisar a atuação do design como instrumento a serviço do desenvolvimento sustentável local na rede de dormir artesanal na Associação Xique-Xique, em Pedro II- Piauí, em sua dimensão sociocultural e econômica.

\section{RESULTADOS}

Com relação aos objetivos propostos, a pesquisa constatou que o ofício das redes de dormir artesanais tem um grande valor cultural para as tecelãs da XiqueXique. A prática, repassada entre gerações, consiste no trabalho e faz parte da história de vida dessas mulheres. Como pontua a tecelã 8: " Faz parte do trabalho da gente, da história da gente desde pequeno. Que já nasci e me criei veno meus tio, fazendo essas redes tudo".

De tal modo, com o passar dos anos, construíram uma relação de identificação com o seu fazer, mas questões sociais e econômicas também se apresentaram determinantes para a permanência das tecelãs na prática. São mulheres de baixos níveis de renda e instrução, portanto, com poucas possibilidades de trabalho no mercado local. Desenvolvem o ofício, também, por necessidade financeira. A renda obtida, mesmo pequena, é bem-vinda. Serve para cobrir despesas cotidianas, sendo um importante complemento de renda. Como revela o depoimento da tecelã 4: "[...] Ajuda a pagar uma luz, uma água. Se não fosse eu trabalhar como artesã eu tinha só o meu dinheirinho dos aposento para tudo, pra tudo e tinha que dá."

A Associação desempenha um papel importante nesse processo. Mesmo com a desvalorização do produto no mercado local, mantém a rede de dormir artesanal na sua linha de produção, colaborando para a manutenção dessa prática e geração de renda na comunidade. Além disso, a oficina da associação tornou-se um espaço de convívio social. É o momento, seja na produção ou na hora do lanche, em que cooperam entre si, compartilham conhecimento e experiências do seu dia a dia. Com isso, promove cidadania e inclusão social às tecelãs através do seu saber fazer. Logo, essa atividade está em sintonia com a noção contemporânea de sustentabilidade, que 
compreende também os conceitos de economicamente inclusivo e socialmente justo (BORGES, 2011).

Sobre a técnica de tecer, é representativa de uma cultura de caráter secular na região. Desde a implantação da atividade, permanece o mesmo processo de produção, com seus métodos e equipamentos. Foram descritas as técnicas de tecer nos teares de grade e de macaco, com os respectivos tipos de redes de dormir artesanais que produzem. A Xique-Xique desenvolve três tipos de tramas, tais como, Tapuerãna (Foto. 01), Batida ou Caruá (Foto 02) e Olho de Pombo (Foto 03). Dessas tramas são produzidos oito tipos de redes - Tapuerãna (Foto 04), Catada (Foto 05), Três panos, Olho de Pombo, Batida ou Caruá, Quadro virado, Duas Capas, e Talo. Os dois últimos modelos estão fora da linha de produção, pois exigem maior tempo e esforço para serem produzidos. O retorno financeiro é pequeno e não compensa para a associação confeccioná-las. As tecelãs não sabem a origem dessas tramas e tipos de rede, exceto a técnica da rede Catada, que foi ensinada durante curso de capacitação promovido pela $\mathrm{LBA}^{8}$ na década de 1980 .

Foto 01 - Trama Tapuerãna

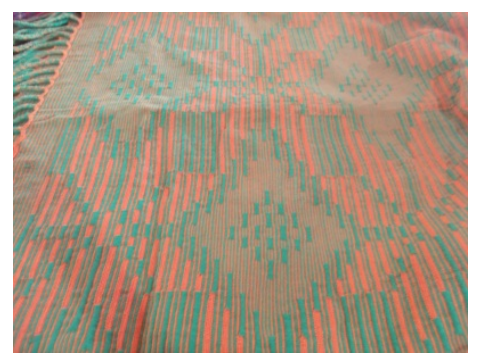

Fonte: produção da autora
Foto 02 - Trama Batida

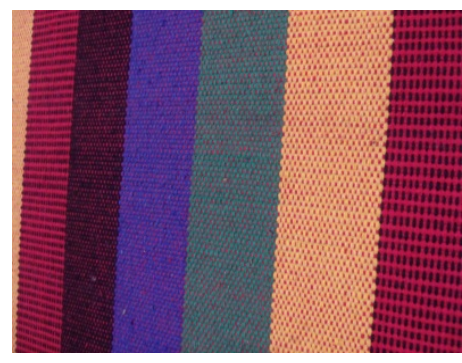

Fonte: produção da autora
Foto 03 - Trama Olho de pombo

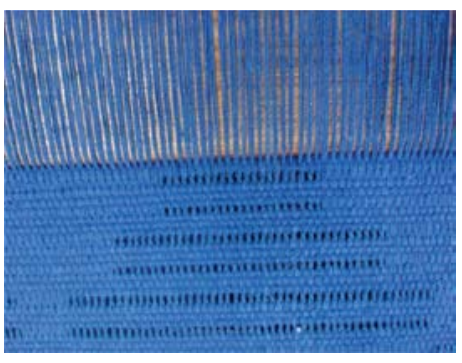

Fonte: produção da autora
Foto 04- Rede Tapuerãna

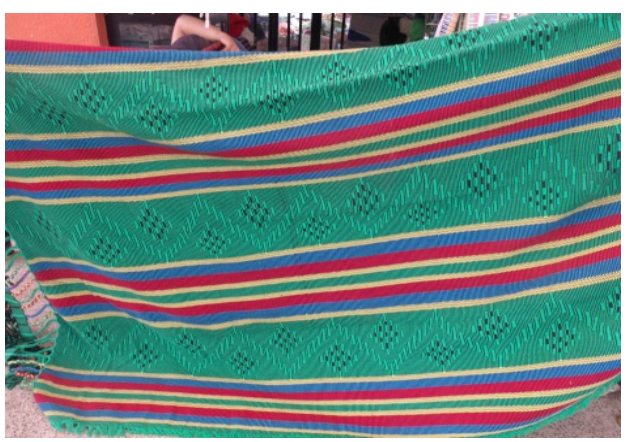

Fonte: produção da autora
Foto 05- Rede Catada no tear

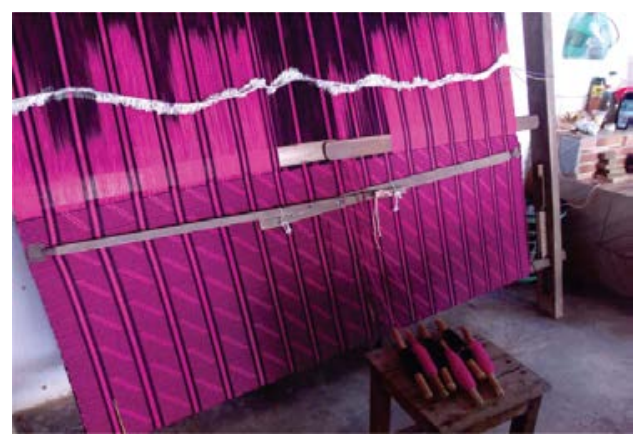

Fonte: produção da autora

Os elementos figurativos são variados e aplicados, especialmente, nas redes Tapuerãna e Catada. As representações são simples e compõem desenhos geométricos ou figurativos. São criados e renomeados fazendo referência a formas reais e presentes no cotidiano das tecelãs. Na Tapuerãna permanecem os mesmos desenhos aprendidos na infância, tais como, flor ou quatro bolos (Foto 06), penas, caracol e x, estrela ou oito folhas (Foto 07), borboleta e quadro.

\footnotetext{
8 Legião Brasileira de Assistência
} 
$\mathrm{Na}$ Catada, os desenhos são em maior número; foram identificados o mandacaru (Foto 08), borboleta, capim e flor, peão aberto e fechado, flor, gregas (Foto 9 ), vezinho ou cotovelinho (Foto 10). Não se sabe a origem dessas figuras, exceto o mandacaru que foi tecido na rede como referência à vegetação característica da região. A relação com o ambiente e a natureza é importante para o artesanato. Os motivos da flora e da fauna servem como ponto de partida para tradições que depois se materializam nos produtos. (BONSIEPE, 2011).

Foto 06 - Flor

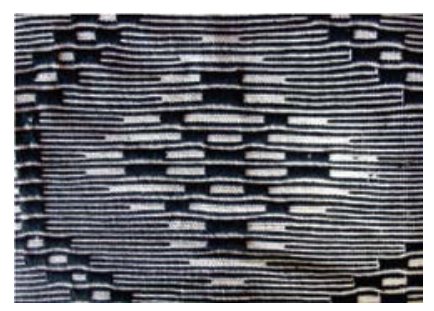

Fonte: produção da autora

Foto 07 - Estrela

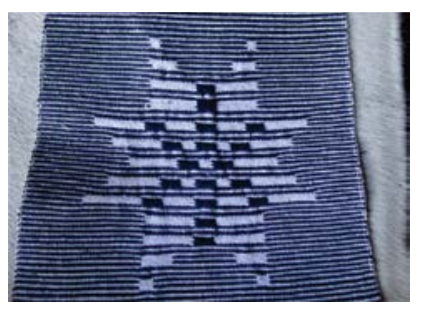

Fonte: produção da autora
Foto 08 - Mandacaru

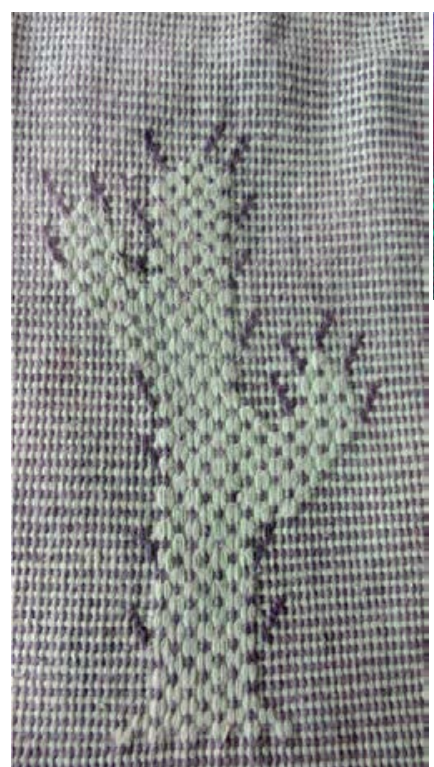

Fonte: produção da autora
Fotos $09-$ Gregas

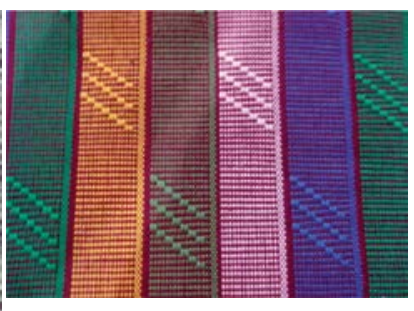

Fonte: produção da autora

Foto $10-$ Vezinho

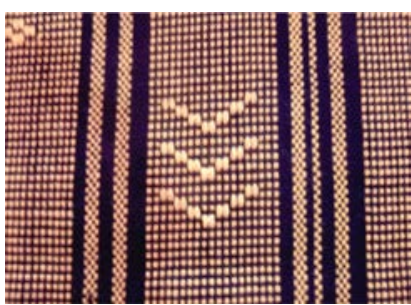

Fonte: produção da autora

No que se refere às ações de design na rede de dormir artesanal, foram evidenciados dois processos de inserção no artefato. Na primeira, promovida pela ARTESOL, no ano 2000, toda a produção foi estruturada e qualificada para o mercado. Nas redes de dormir foi realizado um processo de simplificação, diminuindo a quantidade de desenhos tecidos. Como alguns tipos de redes já estavam deixando de serem feitas, ficou definido com as tecelãs quais permaneceriam na linha de produção e as mais trabalhosas passaram a ser tecidas apenas por encomenda. A ação trouxe benefícios para a organização da produção.

A segunda inserção de design foi realizada, no ano de 2013, pelo SEBRAE. As ações foram de caráter pontual e focadas nos produtos. Dentro da linguagem característica da tecelagem da Xique-Xique, foram criados novos modelos de redes (Foto 11 e 12) e outros, como na primeira inserção, apenas simplificados, com a diminuição da quantidade de desenhos (Foto 12 e 13). No que tange às redes de dormir artesanais, ambas as ações de design não resultaram num retorno financeiro satisfatório para as tecelãs. Como Revela a presidente da Xique-Xique: “ [...] A rede do designer é muito bonita, mas ela fica muito cara e demora para tecer porque é toda catada no tear. Ela ficou a $\mathrm{R} \$ 300,00$ reais. Ficou cara. A gente ainda vendeu pra São Paulo. Pra esse comércio aqui não tem saída. Aqui tem que ser um outro padrão. Tem mais retorno fazer as coisas mais simples." 
Foto 11 - Tecelã aplicando franjas as redes com inserção de design

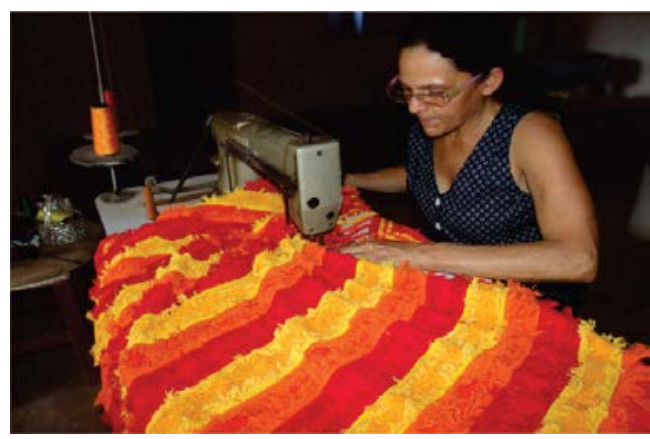

Fonte: produção da autora

\section{Foto13 - Rede Tapuerãna com inserção de design. Menos desenhos no tecido}

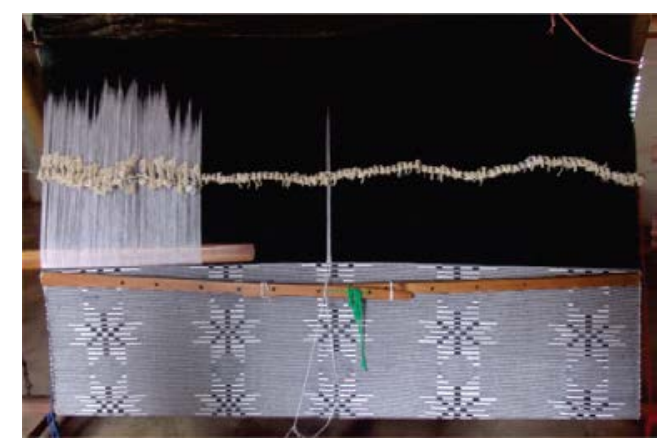

Fonte: produção da autora
Foto 12- Rede com inserção de Design

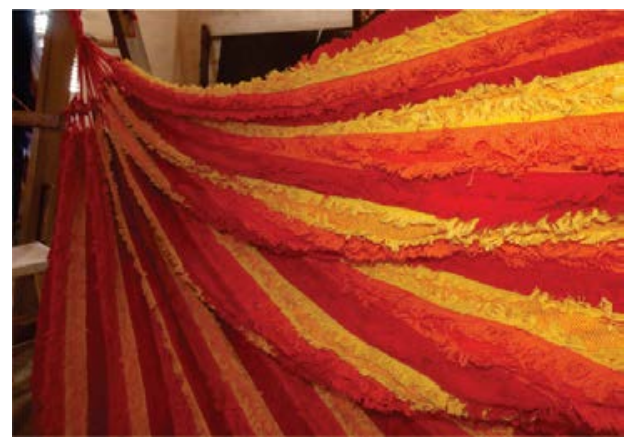

Fonte: produção da autora

Foto14 - Rede Tapuerãna com inserção de design. Menos desenhos no tecido

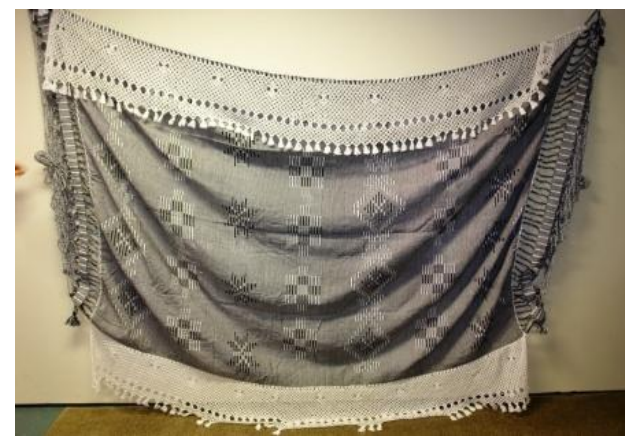

Fonte: Carlos Lima (SEBRAE, 2012)

Para facilitar a análise dessas ações de design na rede de dormir artesanal da Associação Xique-Xique foi desenvolvido o quadro comparativo, abaixo, relacionando as ações de design, as premissas do desenvolvimento sustentável local e os resultados. Com base no referencial teórico, foram consideradas, apenas, as premissas específicas para a análise do design como uma ferramenta que pode agregar valor às redes de dormir artesanais e, assim, gerar resultados que se revertam em desenvolvimento sustentável local na Associação Xique-Xique. 
Quadro 01- Quadro comparativo das ações de design e premissas do desenvolvimento sustentável local

\begin{tabular}{|c|c|c|}
\hline Ações de design & Premissas DSL & Resultados \\
\hline \multirow[t]{2}{*}{$\begin{array}{l}\text { a) Organização e definição da linha } \\
\text { de produção; } \\
\text { b) Qualificação do produto para o } \\
\text { mercado: padrões de medidas, } \\
\text { acabamento, combinação de cores; } \\
\text { seleção dos desenhos e da matéria- } \\
\text { prima; } \\
\text { c) Qualificação do processo de } \\
\text { produção; } \\
\text { d) Comercialização: formação de } \\
\text { preço, apresentação do produto, } \\
\text { produção de catálogo. } \\
\text { e) Desenvolvimento de novos } \\
\text { produtos; } \\
\text { f) Fortalecimento da organização } \\
\text { social. }\end{array}$} & $\begin{array}{l}\text { Agregação de valor na } \\
\text { cadeia produtiva }\end{array}$ & $\begin{array}{l}\text { Resultados positivos: } \\
\text { Ampliou a competitividade dos } \\
\text { outros produtos (bolsas, jogos } \\
\text { americanos, tapetes, mantas) no } \\
\text { mercado; Organização da produção } \\
\text { para o mercado; Melhoria dos } \\
\text { processos produtivos; Inserção de } \\
\text { novos produtos: cachecóis, mala de } \\
\text { viagem e novos modelos de redes; } \\
\text { Divulgação através do catálogo e } \\
\text { participação em eventos; Aumento } \\
\text { da qualidade dos produtos: } \\
\text { acabamento, padrões de medidas, } \\
\text { uso de matéria-prima de } \\
\text { qualidade, combinação das cores e } \\
\text { seleção dos desenhos, retirando os } \\
\text { excessos. } \\
\text { Resultados negativos: } \\
\text { Não ampliaram a competitividade } \\
\text { das redes no mercado local. Não } \\
\text { houve retorno satisfatório em } \\
\text { termos de comercialização; Poucas } \\
\text { tecelãs absorveram as orientações } \\
\text { sobre a formação de preço; A } \\
\text { produção de redes com inserção de } \\
\text { design não foi direcionada, até o } \\
\text { momento, para novos mercados. }\end{array}$ \\
\hline & $\begin{array}{l}\text { Distribuição de ativos } \\
\text { sociais e econômicos }\end{array}$ & $\begin{array}{l}\text { As ações nas redes de dormir não } \\
\text { promoveram o aumento da } \\
\text { geração de renda para as tecelãs. } \\
\text { Portanto, os resultados das ações } \\
\text { não se reverteram em melhoria da } \\
\text { qualidade vida; As ações referentes } \\
\text { aos outros produtos, processo } \\
\text { produtivo e estruturação da } \\
\text { produção contribuíram para } \\
\text { geração de renda e a permanência } \\
\text { das tecelãs no seu ofício. } \\
\text { Fortalecimento da associação; } \\
\text { Ganho de conhecimento e } \\
\text { capacitação tecnológica sobre } \\
\text { produto e processo. }\end{array}$ \\
\hline
\end{tabular}

Fonte: Elaborado pela autora, com base na pesquisa realizada

Segundo a descrição do quadro acima, verificou-se que as ações de design foram positivas quanto à padronização de medidas, acabamento, qualificação do processo produtivo, organização da produção e fortalecimento do trabalho coletivo, capacitando e construindo conhecimento técnico em parceria com as tecelãs. Estes aspectos foram essenciais para a permanência da Associação Xique-Xique no mercado local e, consequentemente, para promover geração de renda na região. Buarque 
(2008) esclarece que qualquer estratégia de promoção do desenvolvimento sustentável local deve estar associada com alguma forma de distribuição de ativos sociais, como conhecimento e capacitação tecnológica.

Entretanto, no que se refere às redes de dormir artesanais da Xique-Xique ainda não foram suficientes para melhorar a competitividade. $O$ mercado local não absorve essas redes com inserção de design. A forte concorrência com a rede industrializada, especialmente a sol a sol, diminui o seu valor comercial. Até o momento, não existe uma estratégia de comercialização e nem um direcionamento para o mercado adequado. De tal modo, ainda não proporcionaram geração de renda suficiente que se reverta em melhoria da qualidade de vida, ou seja, em desenvolvimento sustentável local para a Associação Xique-Xique.

A fim de que as intervenções de design sejam, de fato, eficientes em termos de mercado, e se revertam em desenvolvimento sustentável local para as tecelãs da Xique-Xique, é importante estabelecer parcerias sólidas e concentrar ações - de designers e gestores - em toda a cadeia produtiva. Da aquisição da matéria-prima, passando pelo processo de produção até a divulgação e comercialização. É fundamental buscar o nicho de mercado correto e fortalecer a comunicação entre produtor e público-alvo, isto é, um consumidor que compreenda e valorize a dimensão cultural desse artefato.

\section{CONSIDERAÇÕES FINAIS}

Confirmou-se através da pesquisa que, compreender a complexidade do contexto sociocultural e econômico da produção de redes artesanais da Xique-Xique, é essencial para se desenvolver ações de promoção do desenvolvimento sustentável local mais eficazes. Nesse sentido, inserir o design como agente agregador de valor, capaz de gerar competitividade ao referido produto é um desafio. É importante que as instituições de fomento, gestores e os profissionais de design, conscientes da sua responsabilidade social, cultivem uma visão mais ampla desse processo. Envolver a comunidade, convergir ações em várias esferas locais e não locais, sejam de caráter político, sociocultural, tecnológico ou de mercado e acompanhar o retorno disso para as tecelãs é indispensável para gerar resultados sustentáveis, ou melhor, que possam se reverter em qualidade de vida para as tecelãs.

\section{REFERÊNCIAS}

BONSIEPE, Gui. Design, cultura e sociedade. São Paulo: Blucher, 2011.

BORGES, Adélia. Design mais artesanato: o caminho brasileiro. 1a edição. São Paulo: Editora Terceiro Nome, 2011.

BUARQUE, Sergio C. Construindo o desenvolvimento local sustentável. 4a Edição. Rio de Janeiro: Garamond, 2008.

CARDOSO, Rafael. Uma introdução à história do design. 3a edição. São Paulo: Editora Blucher, 2008.

CARVALHO, Luciana. Artes e ofícios de Pedro II. Rio de Janeiro: IPHAN, CNFCP, 2009.

CASCUDO, Luís da Câmara. Rede de dormir: uma pesquisa etnográfica. 2a ed. São Paulo: Global, 2003. 
CASTELLS, Manuel. O poder da identidade. São Paulo: Paz e Terra, 1999.

CAVALCANTI, Virgínia; AZEVEDO, Luciana. A relação entre o design e os programas de fomento ao artesanato brasileiro. A Casa. São Paulo. 2013. Disponível em: http//: www.acasa.org.br acesso em 25/03/2015.

ECIB. Estudo da competitividade da Indústria brasileira. Relatório Final. IE/UNICAMP, IEI-UFRJ-FDC-FUNCEX, 1993.

YIN, Robert K. Estudo de caso: planejamento e métodos. 2aed. Porto Alegre: Bookman, 2001.

LAKATOS, Eva Maria; MARCONE, Marina de Andrade. Fundamentos da Metodologia Científica. 5a ed. São Paulo: Editora Atlas, 2003.

MANZINI, Ézio. Design para inovação social e sustentabilidade: comunidades criativas, organizações colaborativas e novas redes projetuais. Cadernos do Grupo de Altos Estudos, v.1. Rio de Janeiro: E-papers, 2008. 